\title{
EVALUATION OF THE EFFECT OF HEAT-ADHESIVE EMULSIONS FOR TACK COATS WITH SHEAR TEST FROM THE ROAD RESEARCH LABORATORY OF BARCELONA
}

By

Miró Recasens, Rodrigo

Associate Professor, Civil Engineer, $\mathrm{PhD}$. Technical University of Catalonia Jordi Girona 1-3, Módulo B1, 08034 Barcelona, Spain

Phone 0034934017085, Fax 0034934017264

r.miro@upc.edu

Martínez, Adriana

Assistant Professor, Civil Engineer, PhD. Technical University of Catalonia Jordi Girona 1-3, Módulo B1, 08034 Barcelona, Spain

Phone 0034934017273, Fax 0034934017264

adriana.martinez@upc.edu

and

Pérez Jiménez, Félix

Professor, Civil Engineer, PhD. Technical University of Catalonia

Jordi Girona 1-3, Módulo B1, 08034 Barcelona, Spain

Phone 0034934017085, Fax 0034934017264

edmundo.perez@upc.edu

Submitted for Presentation and Publication at the 2006 Annual Meeting of the Transportation Research Board

Submission date: October 28, 2005

Word count: 6413 


\begin{abstract}
The use of conventional emulsions for tack coats can cause problems as they frequently stick to the tires of construction vehicles. Consequently the bond between the asphalt layers is inadequate. The importance of tack coats in the performance of the pavement means that bituminous emulsions are constantly being improved. Recently, new types of emulsions have been developed from very low penetration bitumen that contains no flux. They are known as "heat-adhesive" emulsions and they are resistant to construction vehicles.

The purpose of this study is to analyze the effect of different heat-adhesive emulsions and to verify their performance in service, in comparison with the response of a conventional emulsion. For this reason a new shear test -the LCB test- has been developed in the Road Research Laboratory of the Technical University of Catalonia. This test is carried out at different temperatures, both on laboratory specimens and on cores extracted from recently constructed pavements, where the same emulsions and dosages have been used.

The application of the LCB test has shown that the performance of the different heat-adhesive emulsions mainly depends on the characteristics of the base bitumen and the kind of modifier used. At low temperatures, heat-adhesive emulsions reach, in general terms, lower shear resistances than conventional emulsions; however, at intermediate temperatures there are heatadhesives emulsions with both higher and lower strengths than those of the conventional emulsions.
\end{abstract}

\title{
INTRODUCTION
}

The level of adhesion between asphalt layers in flexible pavement has influence on their performance. In fact, when considering the distribution of stresses and deformations in an elastic multi-layered system, it can be seen that the lack of adhesion between layers causes a greater deformation in the structure and, consequently, results in a shorter pavement service life.

The use of conventional emulsions for tack coats can cause problems to resist construction vehicles. Once they have cured, the residual bitumen remaining on the surface frequently sticks to the truck tires and disappears in large parts of the treated areas, consequently rendering the treatment less efficient. The importance of tack coats in the performance of the pavement means that bituminous emulsions are constantly being improved. Recently, new types of emulsions have been developed from very low penetration bitumen that contains no flux. They are known as "heat-adhesive" emulsions and they are resistant to construction vehicles. However, the adhesive ability of these new emulsions has not previously been studied closely, particularly at low temperatures.

The test procedures which have previously been used to assess the degree of adhesion between two asphalt layers using a tack coat can be divided into two main types: tensile and shear. In the direct tensile tests, clamps have to be tightened or attached directly onto the material, which makes up each of the layers, although some of them, as the Schenck-Trebel test, used by Litzka et al. (1) in Austria, can be applied on the pavement. This may be difficult to do correctly without causing eccentric loading that distort the test and, moreover, special clamps have to be made for this purpose. These problems could be avoided if indirect rather than direct tensile test were used, as the Wedge Splitting Test, developed by Tschegg et al $(2,3)$, which applies a force to a dual layer specimen, by pushing a wedge into the interface between the two layers until they separate as a result of the horizontal component of the force. 
The second group of tests, which are used to evaluate the bond between layers, are the direct shear tests. For instance, Uzan, Livneh and Eshed (4), of Technion I.I.T. (Haifa, Israel), used a type of direct shear test on a dual layer system of asphalt mixes, varying the temperature, the quantity of tack coat and the vertical force that was applied to the specimen during the test.

Caltabiano and Brunton (5) of Nottingham University, used the Shear Box Test, developed by Hughes (6), in a study on the reflection or propagation of cracks in the asphalt layers of pavements. In a similar way, Molenaar (7) used the direct shear test of Delft University of Technology (Netherlands). The same test procedure is found in the draft copy of the German specification "Testing of layered composite according to Leutner" (8) applied to $150 \mathrm{~mm}$ diameter cores.

More recently, Abdo et al (9) have adapted a direct shear test (US/Belge) on cylindrical specimens, with the specimen dimensions normally used in France (100 mm diameter). Romanoschi and Metcalf (10) used a direct shear test with different levels of normal load to derive the constitutive model for the asphalt concrete layer interface. Mohammad et al. (11) applied a shearing apparatus mounted inside the Superpave shear tester (SST) to determine the optimum application rate of different emulsions for tack coats.

Another new type of test has been developed to determine the bond strength between a thin surfacing system and its substrate. At the required temperature a shearing torque is applied to a metal plate bonded to the surface of the top layer. This procedure, called the torque bond test, has been issued as a Draft for Development by the British Board of Agrément (12), Khweir and Fordyce (13).

The review of the procedures and tests currently used to assess the adhesion between layers shows that there is no one clear and simple procedure that is used by most of the authors.

For this reason the Road Research Laboratory of the Departament of Transportation of the Technical University of Catalonia has developed a new shear test: the LCB (Laboratorio de Caminos de Barcelona) shear test (14) which, unlike existing tests, is better suited to the equipment and the testing proceedures used in Spain. This test is very simple to perform and capable of measuring resistance to tangential stresses caused by a shear force applied to the bond between the two layers.

This test allows both the assessment of the effect of several types of tack coats by testing specimens made in the laboratory, and also the quality control in works by testing the cores. The purpose of this work is to analyze the mechanical response of tack coats while using heatadhesive emulsions and to verify the behavior in service, comparing it with the response of a conventional emulsion.

To this end, the different types of emulsions chosen were: conventional heat-adhesive emulsions, heat-adhesive modified emulsions and conventional emulsion. The LCB shear test was applied at different temperatures and both on laboratory specimens and on cores extracted from the recently constructed pavements where the same emulsions and dosages were used.

\section{LCB SHEAR TEST}

The new LCB shear test that has been developed is based on the experiences mentioned above and aims to simplify the measurement procedure. It is intended to measure the resistance to tangential stresses, caused by the application of a shear force, which are produced in the bond between the two asphalt layers, whether or not a tack coat has been used. The deformation or the displacement of one layer with respect to the other is also measured. 
In the test shear stress is generated in the bond of the asphalt layers to be tested, until it separates them. The specimen is then used as a beam located over two supports, with the test section very close to one of the supports so that the bending moment is almost zero, and the specimen is effectively only subjected to shear stress, figure 1 .

\section{Test of specimens. Tack coats design.}

The specimens manufactured in the laboratory consist of two asphalt layers between which the tack coat to be studied is applied. This dual layer system is prepared in a cylindrical mould 177.8 $\mathrm{mm}$ high and with an interior diameter of $101.6 \mathrm{~mm}$ (15). The asphalt layers are compacted with a Marshall Compactor by applying 100 compaction blows to the upper surface. Once the first layer, of about 10 or $11 \mathrm{~cm}$ height, is compacted, this should be left to cool.

Before applying the tack coat, the upper part of the specimen is sawn off so that the tack coat is applied to a surface without asphalt mortar, which can improve the bond between layers. Placing fresh material on a recently made layer is not the same as placing it on a worn layer, which has no bitumen on its surface. Therefore, the specimen is cut by positioning it in the mould so that it is partly protruding. The upper part is sawn off and then the specimen is repositioned so that the tack coat can be applied and the next layer can be compacted. Before adding the second layer, the required quantity of emulsion to be assessed is applied with a brush and then left until the emulsion breaks.

Next, the hot bituminous mixture used for the top layer is poured on and compacted. Finally, the specimen is partially extruded from the mould so that the joint between the layers is $5 \mathrm{~mm}$ beyond the top of the mould.

The test is performed locating the mould with the specimen inside horizontally over a base prepared with two supports $20 \mathrm{~cm}$ apart. The mould rests on one support and the upper layer of the specimen on the other one; in such a way that the joint between the layers is at $5 \mathrm{~mm}$ from this support and therefore, the mould edge will be at $10 \mathrm{~mm}$, figure 2 .

The joint needs to be far enough from the support to allow the specimen to break readily along the plane of the bond, but the distance must be small so that there is no bending moment in the test. A distance of $5 \mathrm{~mm}$ was decided on based on the experience of Uzan et al (4). In their direct shear test a horizontal force was applied to a dual layer system consisting of prismatic specimens positioned at this distance from the bond between the layers.

The loading piston is located over the metallic mould, $10 \mathrm{~cm}$ apart from each support, and a load at a constant deformation speed of $1.27 \mathrm{~mm} / \mathrm{min}$ is applied. The test was performed at a slow speed in order to obtain a better appreciation of the adhesive effect of the different emulsions. These differences would be scarcely noticeable if the test was at a faster speed, especially at lower temperatures. The speed selected by Uzan et al. (4) was $2.5 \mathrm{~mm} / \mathrm{min}$. However, this value is not normally preset in the more basic presses, which are available in most test laboratories and it must be remembered that one of the reasons for the development of the LCB test is to provide a standard tool for assessing finished work.

Thus the speed of $1.27 \mathrm{~mm} / \mathrm{min}$ was selected. This was considered slow enough for the purposes of the test and, as it is the speed used for the CBR test, it is a default speed setting for the more basic load presses.

The load-deformation data are collected using a suitable computerized data acquisition system.

The equation which provides the value of the shear strength on the bond joining both parts is: 


$$
\tau=(P / 2) / S
$$

where: $\tau$ is the shear strength, $\mathrm{P}$ is the maximum failure load and $\mathrm{S}$ is the cross-sectional area of the specimen.

Other parameters can also be obtained from the test, such as the shear modulus (the relationship between maximum tension and displacement) or the specific cracking energy (the area below the load-displacement curve divided by the cracking area). These parameters also characterise the adhesive bond between layers. However, it has been only considered the peak shear strength so as to facilitate the use of the test for quality control and to minimise the effect of any deformations that could occur in the mixtures near the supports during the test.

\section{Test of extracted cores. Tack coats control.}

The same test procedure can be applied to cores extracted from the road. The cores, which consist of at least two layers, are placed in a cylindrical clamp, which is tightened using bolts to hold them in the required position, in a similar way to the laboratory molded specimens, figure 3.

If the test temperature is different from the room temperature, the specimens are placed in a temperature-controlled environment (oven or refrigerator) until they reach the required temperature. Although it is advisable to have a test press with a temperature controlled chamber in order to keep the test temperature constant, the test is performed at such a speed that there will be no significant temperature change if the test is performed at room temperature.

The test method also has made it possible for cores and laboratory specimens to be tested at the desired temperature after being submerged in water for a certain time at a specified temperature.

\section{Test variability}

In earlier stages of the development of the test, the variability of the results for a wide range of test conditions (different types of emulsions, different test temperatures, testing in dry conditions and after immersion) was studied by the authors.

The variation coefficients are low when the tests are carried out on specimens manufactured in laboratory. The mixture for the upper and lower layers is always the same, so the emulsion used for the tack coat is the only variable. In this case, the variation coefficients for the shear strength of laboratory specimens range between $1 \%$ and $9 \%$, calculated from three individual results.

On the other hand, the results obtained on cores extracted from different roads have higher dispersion because the mixture of the upper and lower layer is not always the same (different mixture composition, different bitumen type, different bitumen content, different compaction, different voids content, etc.). In this case, the variation coefficients range between $6 \%$ and $25 \%$, where the number of individual results to calculate mean values ranges between 2 and 5.

\section{APPLICATION OF LCB SHEAR TEST TO ASSESS THE EFFECT OF HEAT- ADHESIVE EMULSIONS}

Four hard residual heat-adhesive emulsions have been used in this study, two conventional (HAE-1 and HAE-2) and two modified with polymers (HAmE-1 and HAmE-2). The modifiers 
were SB polymer and latex respectively. The fifth emulsion was a conventional rapid setting cationic emulsion (RSCE), manufactured with a 150/200 penetration bitumen, and this will be used as reference. The characteristics of these five emulsions are shown in table 1 . The quantity of emulsion used for the tack coats was $350 \mathrm{~g} / \mathrm{m}^{2}$ in all cases.

The quantity of emulsion normally used for adhesive tack coats is about $400 \mathrm{~g} / \mathrm{m}^{2}$. However, as heat-adhesive emulsions normally have higher bitumen content than conventional emulsions, this value falls slightly to a fixed $350 \mathrm{~g} / \mathrm{m}^{2}$.

In the first part of the study the bond given by these emulsions was determined by testing specimens manufactured in the laboratory. In the second stage, this same property was determined by testing cores extracted from experimental sections of a constructed pavement, where the same emulsions and the same dosages were used.

\section{Test of specimens}

For the upper and lower layers of the specimens it was used a dense mixture manufactured with calcareous aggregates with a maximum size of $8 \mathrm{~mm}$ and a bitumen content of $5.0 \%$ on aggregates. The bitumen of the mixture was modified with polymers, with a penetration between 15 and $30 \mathrm{~mm} \cdot 10^{-1}$ and softening point higher than $70^{\circ} \mathrm{C}$ (according to the Spanish Technical Specifications for modified bitumens).

The tests were performed at a constant speed of deformation of $1.27 \mathrm{~mm} / \mathrm{min}$. The test temperature was varied from low temperatures $\left(-15^{\circ} \mathrm{C}\right)$, where the emulsion has a brittle behavior (especially the hard residual emulsions) to middle temperatures $\left(20^{\circ} \mathrm{C}\right)$.

As an example, the average curves obtained for each of the emulsions can be seen in figure 4 , at a temperature of $+5^{\circ} \mathrm{C}$. Generally, heat-adhesive emulsions show very similar load slopes (before breaking), that is the reason why displacement at maximum stress is highly dependent on the value of load obtained: the higher the load, the higher the displacement. On the other hand, if HAE-2 is compared with HAmE-2, it is observed that both reach similar loads, but the displacement of the modified emulsion is greater, which reveals the higher breaking energy developed by the latter, which is modified and made from a softer base bitumen.

The variation of average resistance for each one of them with the temperature is represented in figure 5 , with the test performed at temperatures of $-15,-5,+5$ and $+20^{\circ} \mathrm{C}$ respectively. Each of the average values has been calculated from three individual results.

The first observation is that, for all of the analyzed emulsions, the lower the test temperature, the higher the shear strength. However, the increase in the strength that can be seen when lowering the temperature varies according to the kind of emulsion. Thus, the strength of emulsions HAE-1 and HAmE-2 increases as the temperature decreases until $-5^{\circ} \mathrm{C}$, but remains constant from this value downwards, while the strength continues increasing until $-15^{\circ} \mathrm{C}$ for the rest of emulsions.

From the results obtained at low temperatures $\left(-15^{\circ} \mathrm{C}\right)$ it can also be observed that the emulsions with a higher shear resistance are conventional RSCE and heat-adhesive modified HAmE-1, with very similar values around 4.4 MPa. The values obtained for heat-adhesive emulsions HAE-2, HAE-1 and HAmE-2 are below them, in that order. The latter has the lowest strength, of $2.6 \mathrm{MPa}$.

On the other hand, the tendency between 5 and $20^{\circ} \mathrm{C}$ is different; it is the heat-adhesive emulsion HAE -1 (harder base bitumen) which shows more resistance, followed by the heat- 
adhesive modified emulsion HAmE-1. Conventional emulsion and the others heat-adhesive emulsions show lower values.

Therefore, the resistance of heat-adhesive emulsions at low temperatures depends significantly on the characteristics of the base bitumen and/or its modification. Heat-adhesive emulsions are the most critical at low temperatures $\left(-15^{\circ} \mathrm{C}\right)$ since they can develop less adhesion ability. Differently, at intermediate temperatures $\left(5\right.$ and $\left.20^{\circ} \mathrm{C}\right)$ there are heat-adhesive emulsions that provide good adhesion ability, even higher than the values reached with the conventional emulsion.

Besides, the shear strengths of the considered emulsions are higher than the shear stresses due to a standard load over the pavement. According to the solution given by Foster and Ahlvin (16), who presented a series of charts for determining the stresses in a pavement due to a circular loaded area, the most unfavorable shear stress obtained when a load of $3.25 \mathrm{t}$ is applied over an area with a radius of $12.5 \mathrm{~cm}$, is about $0.20 \mathrm{MPa}$, decreasing significantly with the distance to the surface.

\section{Test of cores}

Among these emulsions, three of them: HAE-1 HAmE-1 and RSCE, were applied as tack coats during the construction of a pavement, in three separate sections. They were applied between the wearing and binder courses, made with semi-dense bituminous mixtures, with a maximum aggregate size of 12 and $20 \mathrm{~mm}$ respectively, both with 60/70 pen bitumen, using the same coat dosage as before $\left(350 \mathrm{~g} / \mathrm{m}^{2}\right)$.

Cores were extracted from the pavement during two different periods: 3 and 16 months after construction. Then, the cores were tested for shear stress resistance at two different temperatures, +20 and $-15^{\circ} \mathrm{C}$. The aim was to assess the actual behavior of the heat-adhesive emulsions at a medium temperature and a low temperature, so that the harder residual bitumen of these emulsions would show fragile behavior, decreasing the adhesive ability.

As with the laboratory specimens, three cores were tested for each emulsion and for each test temperature.

At $+20^{\circ} \mathrm{C}$, the average resistances obtained from the cores tested after three months, figure 6, show the same trend as those obtained with specimens tested at the same temperature. Thus, the emulsion with the greater shear resistance is the conventional heat-adhesive emulsion (HAE-1), followed by the heat-adhesive modified emulsion (HAmE-1) and, finally, the conventional emulsion (RSCE).

However, these shear resistances are considerably lower than those obtained from the laboratory specimens. Although it is usual to obtain less resistance from cores than from laboratory specimens, in this case the reduction is more than $50 \%$. The reason could be a less emulsion dosage because of a bad operation of the injectors of the spray bar, which didn't allow the realization of a homogeneous spray; or the fact that the hard bitumen of the emulsion blends with the softer bitumen of the mixtures of the asphalt layers, decreasing the resistance of the cores, in comparison with that of the specimens.

Nevertheless, the strength of conventional emulsion RSCE increases in the long term, while the strength of heat-adhesive modified emulsion HAmE-1 remains constant and the strength of the heat-adhesive emulsion HAE-1 decreases slightly.

Similar comments can be made when analyzing the mean strengths obtained at $-15^{\circ} \mathrm{C}$, figure 7 . In this case, the values obtained for all emulsions are very alike, especially the strengths of the conventional and heat-adhesive modified emulsion, as was observed with the testing of 
the specimens. In the long term, not only this tendency remains, but a slight increase of the strength of the conventional emulsion and a slight decrease in the heat-adhesive emulsion is appreciated.

\section{CONCLUSIONS}

In view of the results obtained with the LCB shear test for each one of the emulsions analyzed in this study, it is possible to conclude that, in general, the heat-adhesive emulsions show less adhesion ability at low temperature, while the performance of heat-adhesive emulsion at intermediate temperatures $\left(5\right.$ and $\left.20^{\circ} \mathrm{C}\right)$ is very conditioned to the characteristics and/or modification of the base bitumen. This means to say that there can be emulsions with better or worse adhesion ability than the conventional emulsions.

Furthermore, the performance in the short term, after the laying, proves the tendency observed with the testing of samples, showing a considerable decrease of strengths with regard to these samples, probably due to the less emulsion dosage as a consequence of a deficient application of the tack coat.

In spite of this fact, the shear strength of the conventional emulsion RSCE improves in the long term, while the strength decreases for the heat-adhesive emulsions, both conventional and modified, especially at low temperatures, when their response is actually the most critical. This fact gives evidence of the more noticeable effect of aging in heat-adhesive emulsions (due to the low penetration base bitumen) than in conventional emulsions from a soft residue.

To sum up, the LCB shear test has allowed assessing the differences of performance between heat-adhesive emulsions and conventional emulsions, displaying a behavior somewhat more critical at low temperatures, although the differences observed are not very important and the strength values obtained are good enough to ensure the bonding between layers.

\section{REFERENCES}

1. Litzka, J. H., Pass F. and Zirkler, E. Experiences with thin bituminous layers in Austria. In Transportation Research Record: Journal of the Transportation Research Board, No. 1454, TRB, National Research Council, Washington D.C., 1994, pp. 19-22.

2. Tschegg E.K., Kroyer G., Tan D., Stanzl-Tschegg S. and Litzka J. Investigation of bonding between asphalt layers on road construction. Journal of Transportation Engineering, vol.121, No. 4, 1995, pp. 309-316.

3. Tschegg E.K. An efficient fracture test method for bituminous materials and layer bonds. Mechanical Tests for Bituminous Materials. Editors Di Benedetto \& Francken, RILEM, 1997, pp. 405-411.

4. Uzan J., Livneh M. and Eshed Y. Investigation of adhesion properties between asphalticconcrete layers. Asphalt Paving Technology, vol. 47, Proceedings of the Association of Asphalt Paving Technologists, Technical Sessions, 1978, pp. 495-521.

5. Caltabiano M.A. and Brunton J.M. Reflection cracking in asphalt overlays. Asphalt Paving Technology, vol. 60, Proceedings of the Association of Asphalt Paving Technologists, Technical Sessions, 1991, pp. 310-332.

6. Hughes D.A. Polymer grid reinforcement of asphalt pavements. PhD Thesis. Nottingham University, 1986. 
7. Molenaar A.A.A. Evaluation of pavement structure with emphasis on reflective cracking. Reflective Cracking in Pavement. State of the Art and Design Recommendations. Edited by Rigo, Degeimbre and Francken, RILEM, 1993, pp. 21-48.

8. Forschungsgesellschaft für Straßen- und Verkehrswesen. Prüfung des Schichtenverbundes nach Leutner. Probenahme und Durchführung der Prüfung. 1998.

9. Abdo J., Baroin L., Batut X., Grand E., Guiraud P., Huvelin B., Potier J.M., Sainton A., Sigwald B., Soufflet J.P., Tabaillon C. and Monneraye P. L'étude du collage d'un BBTM sur un revêtement en betón âgé de quelques jours. Un nouveau project de recherche fruit du partenariat CIMBETON/SPECBEA/SNBPE. Revue Générale des Routes, No. 798, 2001, pp. 22-28.

10. Romanoschi S. A. and Metcalf J. B. Characterization of asphalt concrete layer interface. In Transportation Research Record: Journal of the Transportation Research Board, No. 1778, TRB, National Research Council, Washington D.C., 2001, pp. 132-139.

11. Mohammad L. N., Abdur Raqib M. and Huang B. Influence of asphalt tack coat materials on interface shear strength. In Transportation Research Record: Journal of the Transportation Research Board, No. 1789, TRB, National Research Council, Washington D.C., 2002, pp. 56-65.

12. British Board of Agrément. Guideline Document for the Assessment and Certification of Thin Surfacing Systems for Highways. British Board of Agrément, 1998, Working Draft 2, pp. 19-22.

13. Khweir K. and Fordyce D. Influence of layer bonding on the prediction of pavement life. Proceedings of the Institution of Civil Engineers. Transport, No. 156, 2003, pp. 73-83.

14. Miró R., Martínez A., Pérez Jiménez F. Assessing heat-adhesive emulsions for tack coats. Proceedings of the Institution of Civil Engineers. Transport, No. 158, 2005, pp. 45-51.

15. CEDEX. NLT-161/84 Resistencia a compresión simple de mezclas bituminosas. Normas NLT - Ensayos de Carreteras. CEDEX.

16. Huang Y. Pavement analysis and design. Pearson Prentice Hall, Inc., Upper Saddle River, 2004.

\section{LIST OF TABLES AND FIGURES}

TABLE 1: Characteristics of the emulsions studied.

FIGURE 1: Diagram of forces and stresses acting on the specimen in the LCB shear test.

FIGURE 2: Position of the specimen in the press during the LCB shear test.

FIGURE 3: Clamp and position of the core in the press during the LCB shear test.

FIGURE 4: Mean results of LCB shear test on specimens, at $5^{\circ} \mathrm{C}$

FIGURE 5: Mean results of LCB shear test on specimens, at different temperatures.

FIGURE 6: Mean results of LCB shear test on cores, at $20^{\circ} \mathrm{C}$

FIGURE 7: Mean results of LCB shear test on cores, at $-15^{\circ} \mathrm{C}$ 
TABLE 1: Characteristics of emulsions studied.

\begin{tabular}{lccccc}
\multicolumn{1}{c}{ Properties } & RSCE & HAE-1 & HAE-2 & HAmE-1 & HAmE-2 \\
\hline Passing 0.5 mm $(\%)$ & 0 & 0 & 0 & 0 & 0.02 \\
Viscosity SSF, at $25^{\circ} \mathrm{C}(\mathrm{s})$ & 32 & 37 & & & \\
Viscosity SSF, at $50^{\circ} \mathrm{C}(\mathrm{s})$ & & & 24 & 31 & 21 \\
Sedimentation $(\%)$ & 2.5 & 2.5 & & 4 & \\
Distillation residue $(\%)$ & 59.0 & 60.0 & 62.4 & & \\
- Penetration $(0.1 \mathrm{~mm})$ & 165 & 24 & 43 & & \\
- Fraass brittle point $\left({ }^{\circ} \mathrm{C}\right)$ & -15 & +1 & -6 & & \\
Evaporation residue at $163{ }^{\circ} \mathrm{C}(\%)$ & & & & 64.0 & 63.4 \\
- Penetration $(0.1 \mathrm{~mm})$ & & & & 64.0 & 55.5 \\
- R\&B $\left({ }^{\circ} \mathrm{C}\right)$ & & & & 22 & 13.1 \\
- Elastic recovery at $40{ }^{\circ} \mathrm{C}(\%)$ & & & & -4 & -8 \\
- Fraass brittle point $\left({ }^{\circ} \mathrm{C}\right)$ & & & &
\end{tabular}


FIGURE 1: Diagram of forces and stresses acting on the specimen in the LCB shear test.

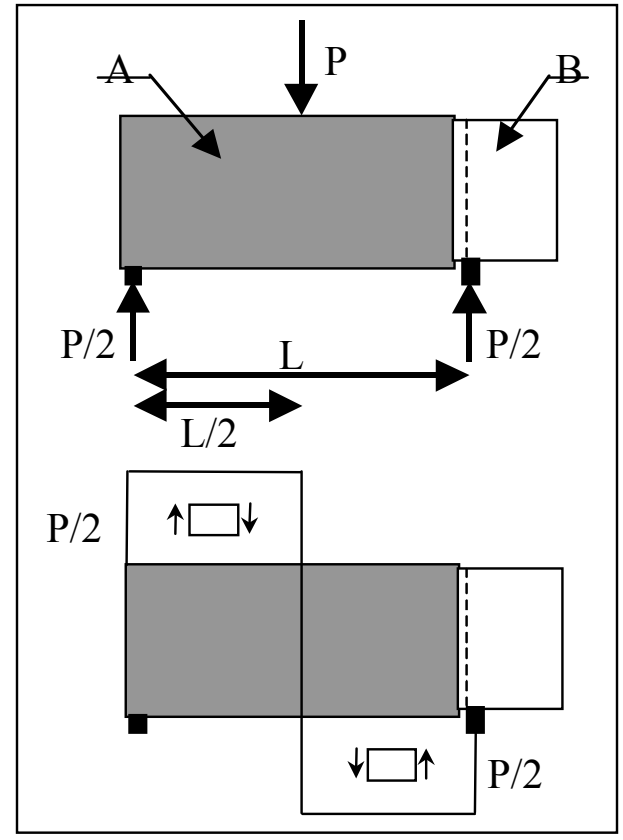


FIGURE 2: Position of the specimen in the press during the LCB shear test.
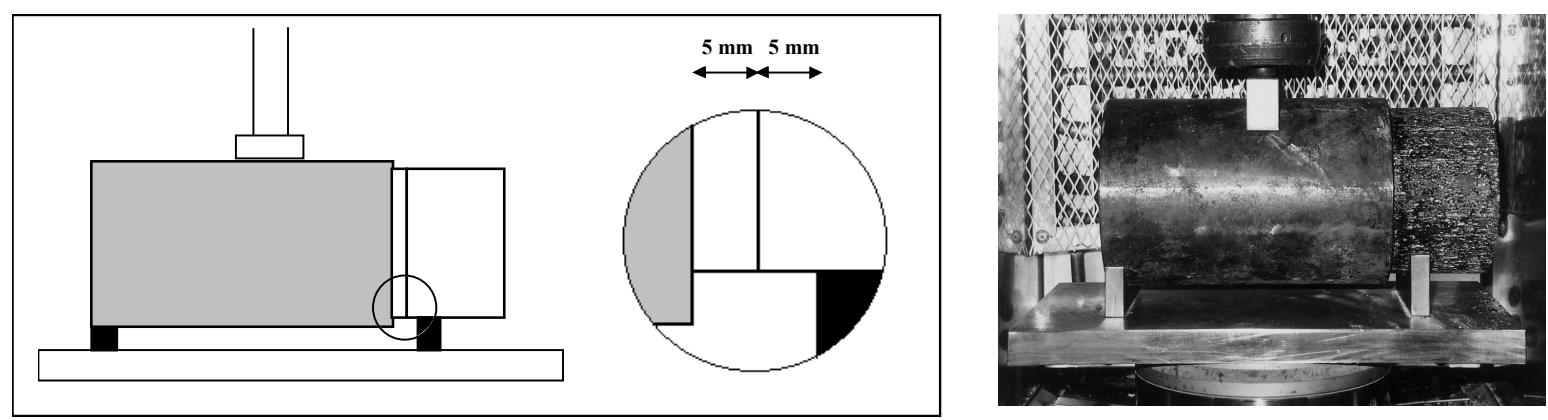
FIGURE 3: Clamp and position of core in the press during the LCB shear test.
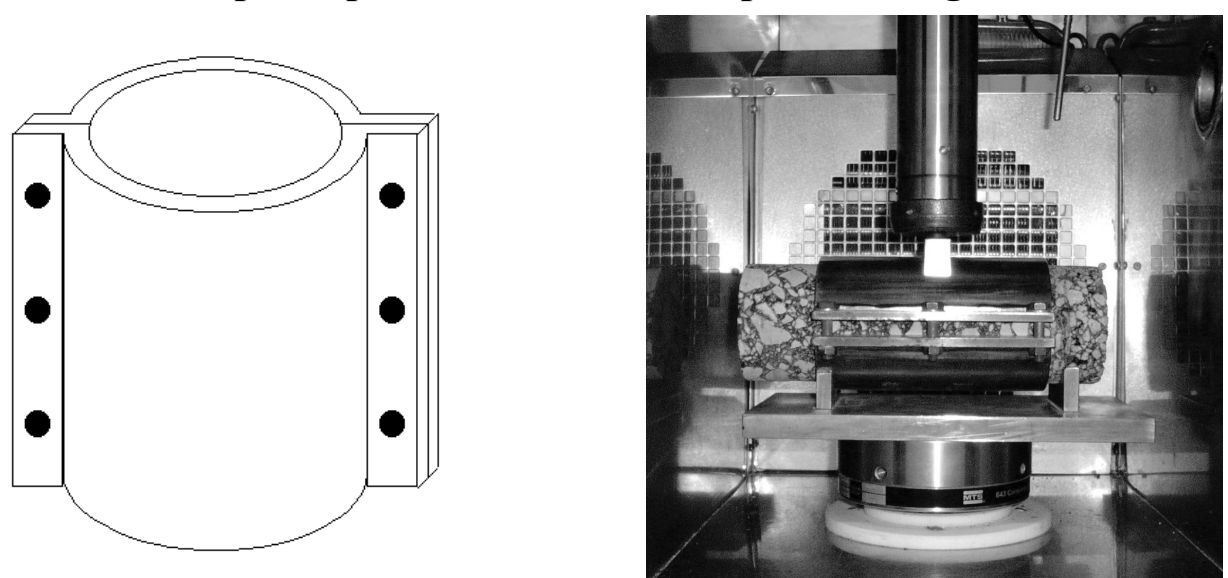
FIGURE 4: Mean results of LCB shear test on specimens, at $5^{\circ} \mathrm{C}$

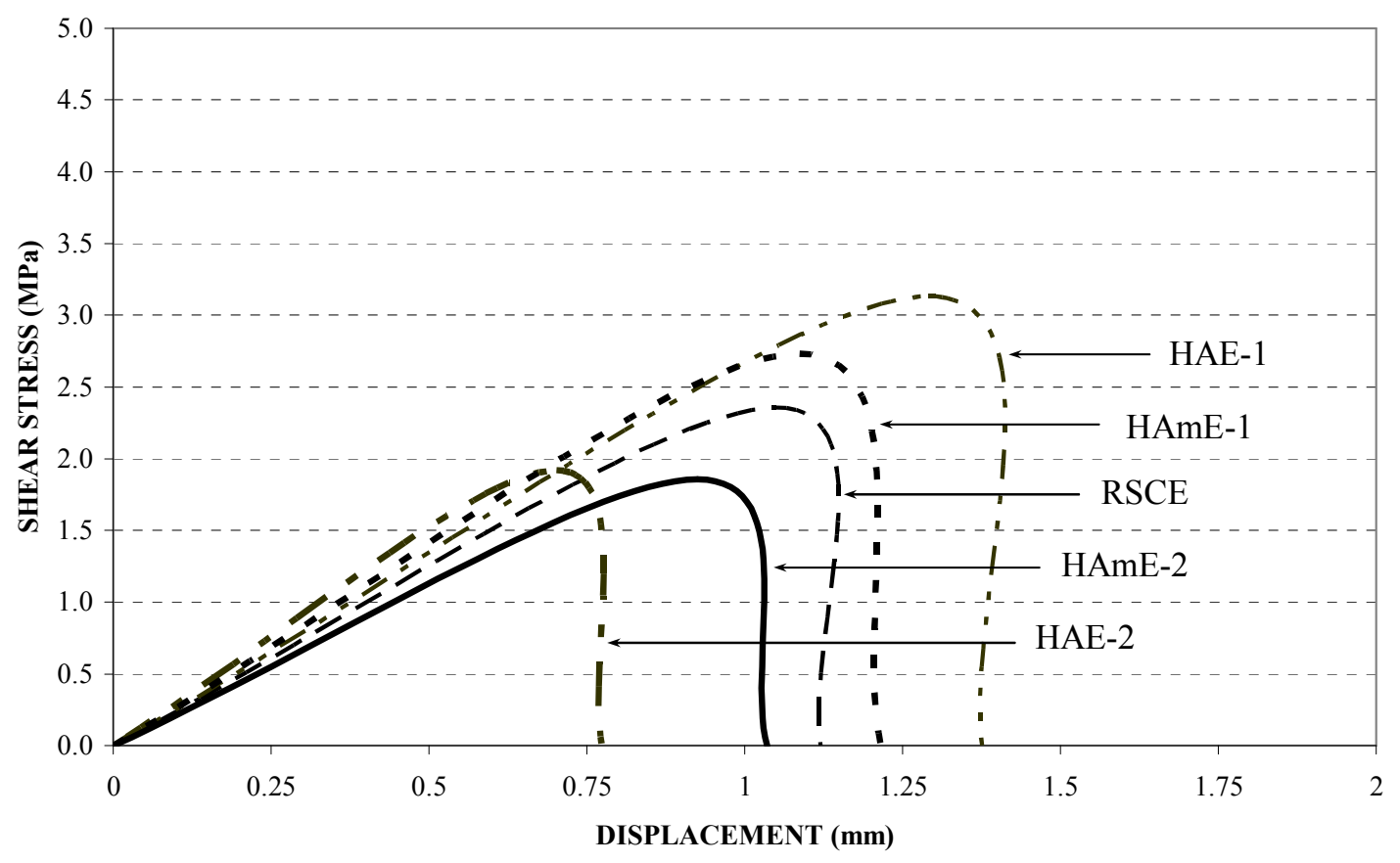


FIGURE 5: Mean results of LCB shear test on specimens, at different temperatures.

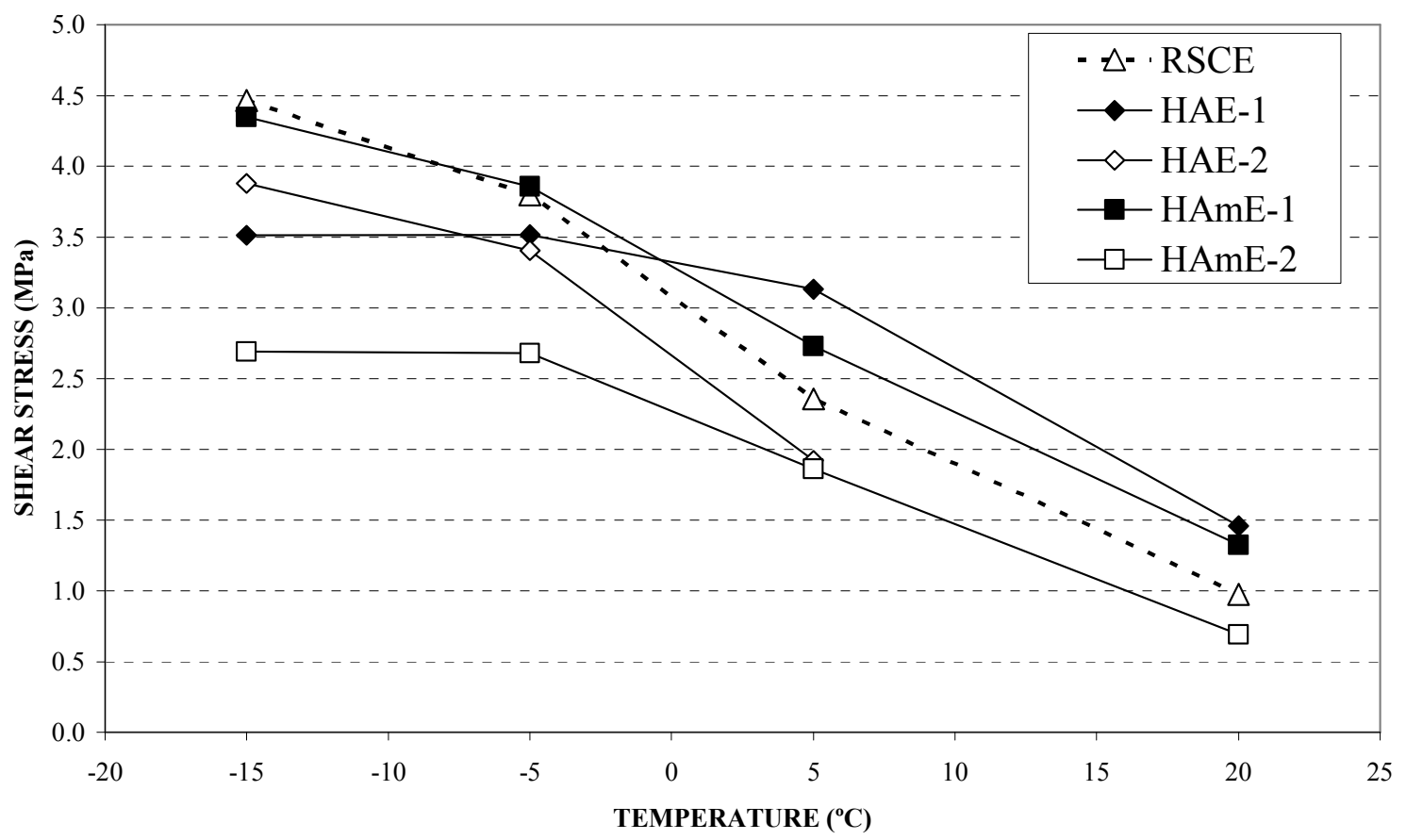


FIGURE 6: Mean results of $\mathrm{LCB}$ shear test on cores, at $20^{\circ} \mathrm{C}$

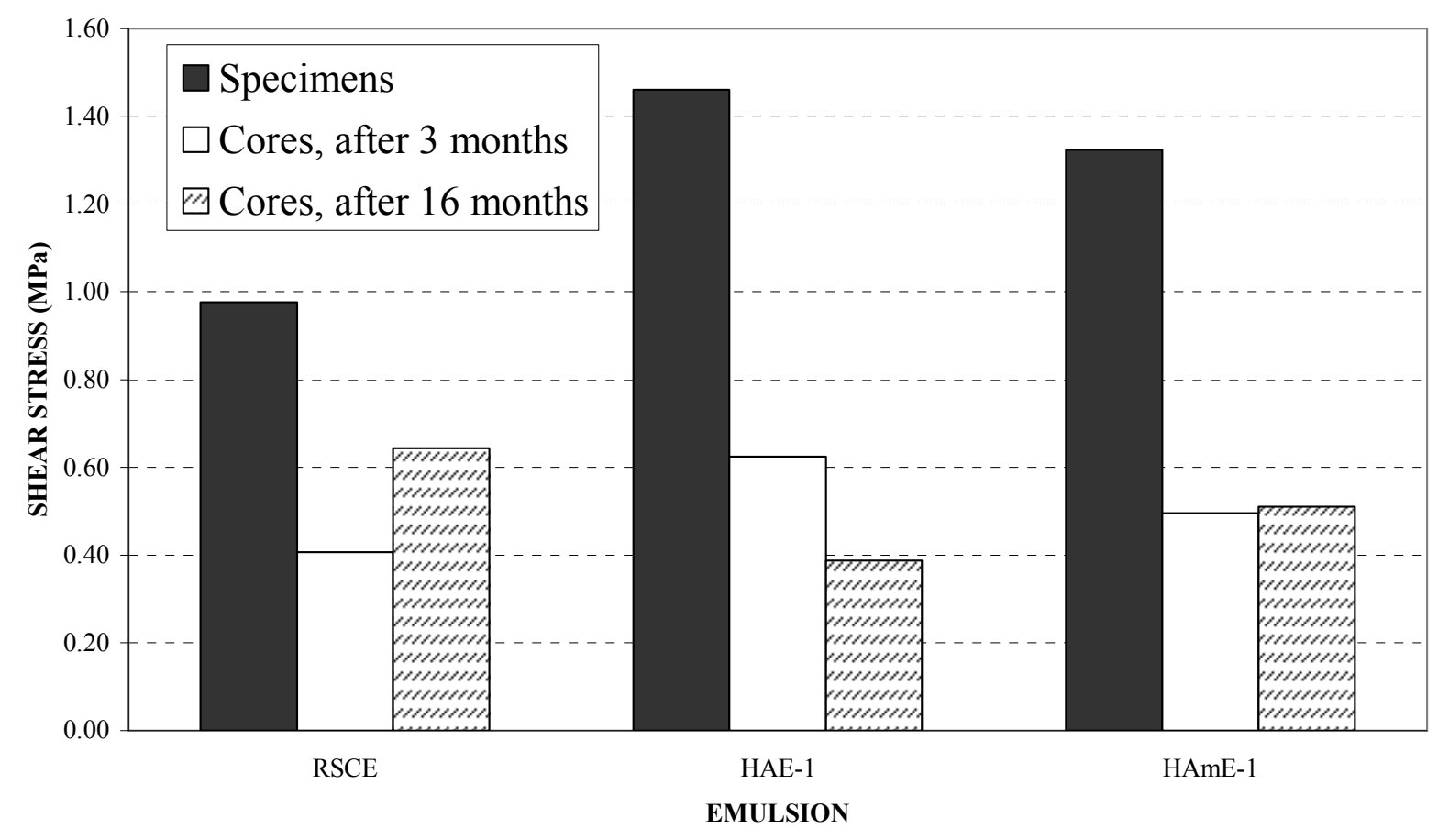


FIGURE 7: Mean results of $\mathrm{LCB}$ shear test on cores, at $-15^{\circ} \mathrm{C}$

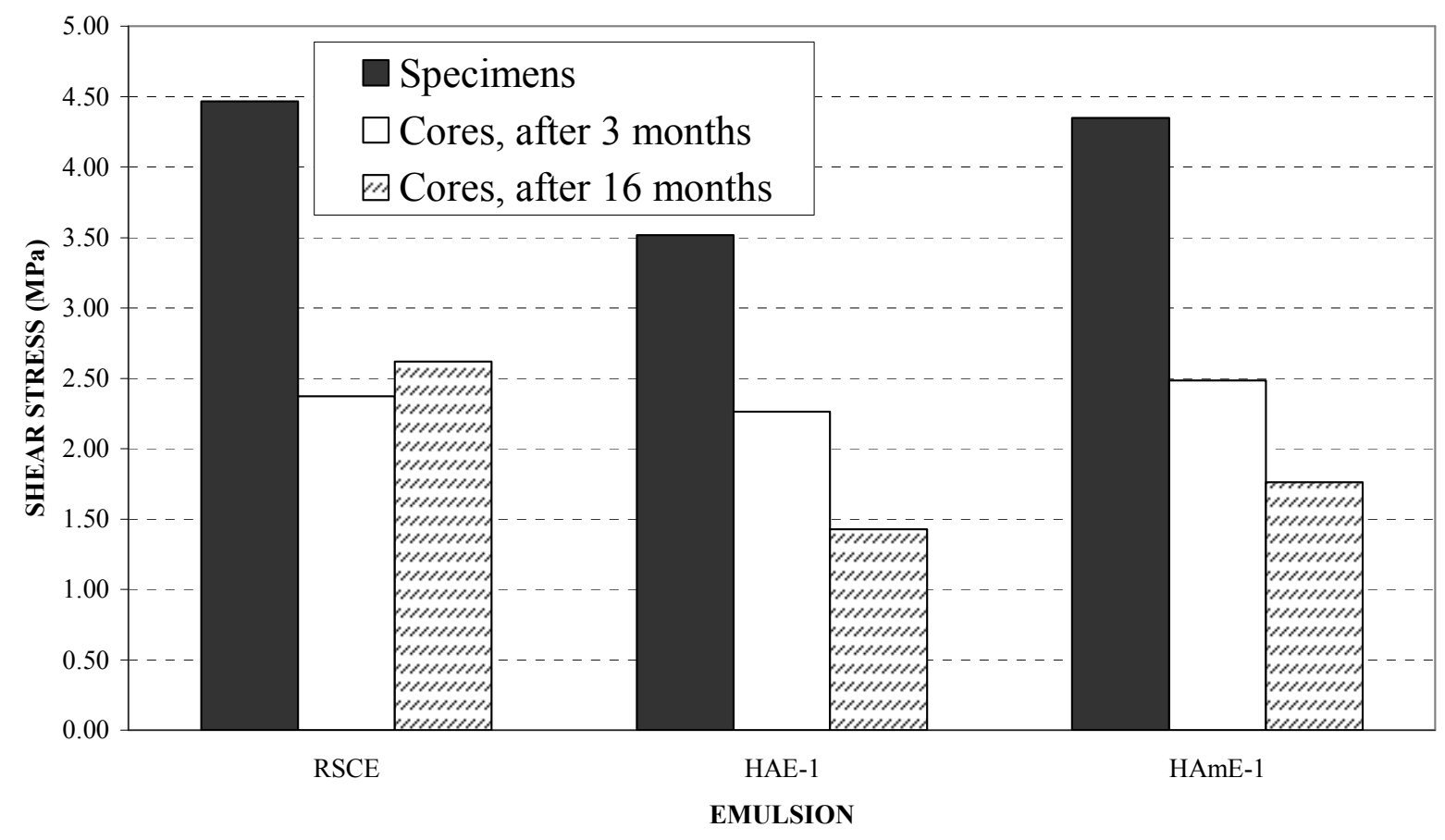

